\title{
Peran Kecerdasan Interpersonal dalam Perspektif Islam pada Siswa Sekolah Dasar di Era Revolusi Industri 4.0
}

\author{
Tasnim Lubis ${ }^{1}$, Nashran Azizan², Maulana Arafat Lubis ${ }^{3}$ \\ ${ }_{1}^{1}$ Politeknik Lembaga Pendidikan dan Pengembangan Profesi Indonesia \\ (LP3I) Medan \\ 23 Institut Agama Islam Negeri Padangsidimpuan \\ Email: tasnimlubis@yahoo.com
}

\begin{abstract}
This article aims to explain the role of interpersonal intelligence in the perspective of Islam in elementary school students in the era of the industrial revolution 4.0. This research is a literature review using descriptive analysis. The results show that innovation that continues to develop initially starts from the industrial revolution 1.0 to 4.0 so that it becomes a challenge and opportunity for educators to develop the potentials that exist in students, so as to create graduates who are competent, characterized and reliable. The presence of the industrial revolution 4.0, in schools is expected to be able to bridge the attitude of students to conform to the Qur'an and the 1945 Constitution and can be integrated in the era of the industrial revolution 4.0.
\end{abstract}

Keywords: Interpersonal Intelligence; Islamic perspective; Learners; Industrial Revolution 4.0.

\begin{abstract}
Abstrak
Artikel ini bertujuan untuk menjelaskan peran kecerdasan interpersonal dalam perspektif Islam pada siswa sekolah dasar di era revolusi industri 4.0. Penelitian ini merupakan telaah pustaka dengan menggunakan analisis deskriptif. Hasil menunjukkan bahwa inovasi yang terus berkembang pada awalnya dimulai dari revolusi industri 1.0 hingga ke 4.0 sehingga menjadi tantangan dan peluang bagi pendidik dalam mengembangkan potensi-potensi yang ada pada peserta didik, agar dapat menciptakan lulusan-lulusan yang berkompeten, berkarakter dan
\end{abstract}


Tasnim Lubis ${ }^{1}$, Nashran Azizan², Maulana Arafat Lubis ${ }^{3}$

dapat diandalkan. Kehadiran revolusi industri 4.0, di sekolah diharapkan mampu menjembatani sikap peserta didik agar sesuai dengan AI-Qur'an dan UndangUndang Dasar (UUD) 1945 serta dapat diintegrasikan di era revolusi industri 4.0.

Kata kunci: Kecerdasan interpersonal; perspektif Islam; peserta didik; revolusi Industri 4.0.

\section{Pendahuluan}

Pendidikan merupakan wujud nyata dalam membenahi sikap dan mental seseorang. Selain itu, untuk meningkatkan kompetensi dalam diri seseorang agar dapat berkembang serta menjadi sumber daya manusia yang dapat diandalkan. Pendidikan merupakan arahan yang diberikan oleh orang yang sudah matang dari segi ilmu dan umur kepada putra putri bangsa untuk meningkatkan kesehatan dan kejiwaan dalam berpikir dan beradaptasi supaya nantinya bisa bermanfaat untuk pribadi dan lingkungannya. ${ }^{1}$ Sedangkan menurut Hamalik ${ }^{2}$ pendidikan merupakan upaya dalam mengemas siswa melalui kegiatan membimbing, megajar, dan melatih untuk masa yang akan datang. Selanjutnya pendidikan berfungsi menyiapkan siswa karena hakikatnya siswa belum mempunyai persiapan, namun harus dipersiapkan dan siswa harus menyiapkan diri. Hal ini bertujuan pada jalan yang akan berproses sebelum siswa turun ke dalam kehidupan yang sebenarnya. Persiapan ini dilakukan agar siswa nantinya dapat bermanfaat untuk dirinya, kemudian menjadi bangsa yang dapat diandalkan untuk negaranya, serta dengan mudah mendapatkan pekerjaan pada waktu yang akan terjadi ke depannya.

1Purwanto Ngalim, IImu Pendidikan Teoritis Dan Praktis (Bandung: PT Remaja Rosdakarya, 2007), hlm. 10.

2Oemar Hamalik, Kurikulum Dan Pembelajaran (Jakarta: Bumi Aksara, 2012), hlm.12. 
Sekolah adalah salah satu bagian dari badan pendidikan. Pendidikan tidak semata-mata terfokus pada peningkatan nilai belajar saja tetapi juga pada perubahan sikap siswa. Imanita ${ }^{3}$ menyimpulkan bahwa terdapat aspek lain yang berpengaruh pada tingkatan skor belajar siswa, yaitu kecerdasan interpersonal. Untuk itu, kecerdasan interpersonal menjadi bagian penting pada proses pembelajaran. Kecerdasan interpersonal menggambarkan kompetensi kepribadian untuk diinterpretasikan terhadap situasi serta kondisi yang ada di sekitarnya.

Dampak arus globalisasi pada dunia pendidikan tentunya memberikan tantangan dan peluang bagi pendidik dalam menyiapkan siswa agar dapat menjadi penduduk Indonesia yang berkompeten, mempunyai sikap yang baik dan terampil dalam bermasyarakat. Perkembangan yang terus maju dari masa ke masa memberikan dampak positif dan negatif bagi pembangunan bangsa. Salah satu perubahan yang terjadi yaitu revolusi industri 4.0. Perkembangan industri yang dimulai dari 1.0 hingga ke 4.0 tentunya memberikan banyak perubahan dan peningkatan yang dapat dirasakan. Untuk menyikapi hal tersebut perlunya sikap yang bijak dalam menerima perubahan zaman yang semakin terus berkembang.

Kecerdasan tidak hanya berpusat pada skor atau nilai saja. Akan tetapi bagaimana siswa mampu memiliki sikap sosial pada situasi yang berbeda. Seperti yang diungkapkan oleh Gardner. Maka dari itu, kecerdasan interpersonal perlu diperhatikan pada setiap proses pembelajaran yang berlangsung. Peserta didik harus dibenahi sejak duduk dibangku sekolah dasar, karena mereka belum terlalu banyak menerima

3M Imanita, "Pengaruh Metode Pembelajaran Dan Kecerdasan Interpersonal Terhadap Hasil Belajar Sejarah Siswa SMA," Jurnal Pendidikan Sejarah Vol. 3, No. 1 (2014), hlm. 45-54, http://journal.unj.ac.id/unj/index.php/jps/article/view/992. 
Tasnim Lubis' ${ }^{1}$ Nashran Azizan², Maulana Arafat Lubis ${ }^{3}$

arus global yang terus berkembang. Peran kecerdasan interpersonal di sekolah diharapkan mampu memperbaiki sikap sosial pada peserta didik. Era digital membuat semua kebutuhan manusia mudah tercapai. Industri 4.0 lahir di negara Jerman, pada saat kegiatan Hannover Fair yang terjadi pada tahun 2011 sekitar 8 tahun yang lalu. ${ }^{4}$ Jerman menjadi salah satu negara yang menjadi dunia manufaktur. Istilah industri 4.0 hanya digunakan pada beberapa negara, sementara untuk dinegara lain memiliki istilah yang berbeda tetapi tetap dengan visi yang sama untuk memajukan daya saing industri pada tiap negara selama menghadapi arus global yang terus bergejolak.

Ciri-ciri manusia yang bermutu yaitu manusia yang meningkatkan kecerdasan dalam dirinya. Kecerdasan tidak hanya terfokus pada nilai semata, tetapi juga perkembangan otak. Umumnya, kecerdasan terbagi dalam beberapa bagian. Oleh karena itu, kecerdasan tidak hanya terletak pada kinerja otak manusia saja, melainkan pada perkembangan sikap sosial manusia itu sendiri. Kata sosial dan interpersonal memiliki makna yang sama. Hal ini sejalan dengan pendapat May Dkk 5 bahwa sosial dan interpersonal hanya berbeda pada pelafalannya saja, namun memiliki makna yang sama.

Kecerdasan interpersonal bagian dari kecerdasan majemuk. Seperti pernyataan Gardner6 menguraikan ada delapan tingkat kecerdasan

${ }^{4} \mathrm{H}$ Kagermann, W.D Lukas, and W Wahlster, "Industrie 4.0: Mit Dem Internet Der Dinge Auf Dem Weg Zur 4. Industriellen Revolution," 2011, http://www.wolfgangwahlster.de/wordpress/wp-

content/uploads/Industrie_4_0_Mit_dem_Internet_der_Dinge_auf_dem_Weg_zur_vierten_in dustriellen_Revolution_2.pdf.

5Lwin May and Dkk, How To Multiply Your Child's Intelligence (Yogyakarta: Indeks, 2008), hlm. 197.

${ }^{6}$ May and Dkk, ..., hlm. 2. 
majemuk, yaitu: (1) linguistik, (2) matematik logis, (3) spasial visual, (4) interpersonal, (5) intrapersonal, (6) musik, (7) kinestetik, (8) naturalis. Dari pelbagai kecerdasan tersebut, kecerdasan interpersonal dapat dibangun dan juga bisa ditingkatkan dalam diri manusia. Oleh karena itu, sebagai makhluk sosial, manusia dapat mengembangkan kecerdasan yang ada pada dirinya, guna meningkatkan kecerdasan yang telah diperoleh sebelumnya.

\section{Metode penelitian}

Penelitian ini merupakan kajian pustaka dimana peneliti mengumpulkan konsep-konsep yang berkaitan dengan kecerdasan interpersonal. Konsep ini dianalisis secara tematis dengan mengkaitkannya dengan sudut pandang Islam atau perfektif Islam.

\section{Hasil dan Pembahasan}

Pada dasarnya kecerdasan sering kali dikaitkan dengan nilai atau prestasi yang diraih oleh seseorang. Seseorang yang mempunyai nilai tinggi maka ia memiliki kecerdasan yang tinggi. Namun, pada dasarnya kecerdasan tidak hanya terfokus pada skor semata. Menurut Amstrong ${ }^{7}$ kecerdasan merupakan kemampuan untuk menangkap situasi baru serta kemampuan untuk belajar dari pengalaman masa lalu. Sedangkan Dariyo ${ }^{8}$ menyatakan bahwa kecerdasan ialah kepiawaian dalam pemecahan masalah dan penyesuaian diri dalam kehidupannya.

${ }^{7}$ Suci Perwita Sari, "Hubungan Verbal Bullying Terhadap Kecerdasan Interpersonal Siswa Di SDN 104206 Sei Rotan T.A. 2013/2014" (Universitas Negeri Medan, 2014), hlm. 9.

${ }^{8}$ Agoes Dariyo, Dasar Dasar Pedagogi Modern (Jakarta: Indeks, 2013), hlm. 93. 
Tasnim Lubis' ${ }^{1}$ Nashran Azizan², Maulana Arafat Lubis ${ }^{3}$

Dari pernyataan argumentasi ahli di atas, maka simpulannya ialah kecerdasan merupakan kemahiran seseorang dalam membaca situasi, sehingga ia dapat menyelesaikan masalah yang sedang terjadi. Kecerdasan tidak hanya berbicara tentang nilai, terlebih bagaimana seseorang bisa menjadi manusia yang tanggap dalam menghadapi situasi dan kondisi.

Kecerdasan interpersonal merupakan kemampuan berhubungan dengan orang lain baik dalam berkomunikasi, mempersepsi, mampu merasakan perasaan serta mampu bekerjasama dengan orang lain. ${ }^{9}$ Uno dan Kuadrat ${ }^{10}$ juga menyatakan bahwa kecerdasan interpersonal merupakan kemampuan seseorang untuk peka terhadap perasaan orang lain. Seseorang yang memiliki kecerdasan interpersonal tinggi lebih cenderung untuk memahami dan berinteraksi dengan orang lain sehingga mudah bersosialisasi dengan lingkungan sekelilingnya.

Berdasarkan pendapat di atas, dapat disimpulkan bahwa kecerdasan interpersonal adalah kemampuan seseorang untuk memahami orang lain dalam berinteraksi atau berhubungan dengan orang lain sehingga dapat membangun hubungan sosial yang baik dan saling menguntungkan. Adapun karakteristik kecerdasan interpersonal menurut ahli sebagai berikut:

9Yessanty Arie Ervani and Ellya Rakhmawati, "Upaya Meningkatkan Kecerdasan Interpersonal Melalui Metode Cooperative Play Pada Kelompok B Di Daqu School International Preschool Semarang Tahun Pelajaran 2014/2015," Jurnal Penelitian PAUDIA Vol. 3, No. 2 (2014), hlm. 194, http://journal.upgris.ac.id/index.php/paudia/article/view/517.

10H Uno and M Kuadrat, Mengelola Kecerdasan Dalam Pembelajaran (Jakarta: Bumi Aksara, 2009), hlm. 13. 
Safaria ${ }^{11}$ mendeskripsikan siswa yang memiliki kecerdasan interpersonal tinggi, yaitu: Pertama, Dapat menumbuhkan dan menghasilkan relasi sosial baru dengan efektif. Kedua, Dapat menolong orang lain dengan suka rela. Ketiga, Dapat memperhatikan relasi sosial secara efektif sehingga tidak musnah dimakan waktu dan senantiasa berkembang semakin intim/mendalam/penuh makna. Kelima, Menyadari akan perubahan sosial yang terjadi disekitarnya dan memahami komunikasi verbal dan non verbal. Keenam, Dapat memecahkan masalah yang terjadi dalam relasi sosialnya dengan pendekatan win-win solusion, serta yang paling penting adalah mencegah munculnya masalah dalam relasi sosialnya. Ketujuh, Memiliki keterampilan komunikasi yang mencakup keterampilan mendengarkan efektif, berbicara efektif dan menulis secara efektif.

Selanjutnya menurut Hoerr ${ }^{12}$, orang yang memiliki kecerdasan interpersonal sangat menikmati permainan kooperatif, senang dan memiliki perasaan empati terhadap orang lain, menunjukkan jiwa kepemimpinan, dan suka menjadi penengah. Adapun ciri-ciri orang yang memiliki kecerdasan interpersonal, yaitu: Pertama, Peka dan mudah memahami perasaan orang lain. Kedua, Mudah berinteraksi dengan orang lain sehingga mudah bersosialisasi dengan lingkungan sekitarnya. Ketiga, Mampu menjalin persahabatan yang akrab dengan teman-temannya. Keempat, Mudah berempati terhadap sesuatu yang terjadi di sekitarnya

${ }^{11} \mathrm{~N}$ Manurung, "Pemanfaatan Multiple Intigence Dalam Proses Pembelajaran," Jurnal Keguruan Vol. 1, No. 1 (2013), hlm. 49-56.

12Zainuddin, "Eksperimentasi Model Pembelajaran Kooperatif Tipe Two Stay Two Stray Dan Number Head Together Pada Materi Pokok Fungsi Ditinjau Dari Kecerdasan Interpersonal Siswa Kelas VIII SMP Negeri Sekota Surakarta" (Universitas Sebelas Maret, 2014), hlm. 28. 
Tasnim Lubis' ${ }^{1}$, Nashran Azizan², Maulana Arafat Lubis ${ }^{3}$

Adapun dimensi kecerdasan interpersonal menurut Anderson ${ }^{13}$, yaitu: (1) sosial sentivity (sensitivitas sosial), yaitu kemampuan siswa merasakan dan mengamati reaksi-reaksi atau perubahan orang lain yang ditunjukkannnya baik secara verbal maupun nonverbal. Siswa yang memiliki sensitivitas sosial yang tinggi, akan mudah memahami dan menyadari adanya reaksi-reaksi tertentu (positif atau negatif) dari orang lain. Indikatornya yaitu empati dan prososial; (2) sosial insight kemampuan seseorang untuk memahami dan mencari pemecahan masalah yang efektif dalam suatu interaksi sosial, sehingga masalah-masalah tersebut tidak menghambat apalagi menghancurkan relasi sosial yang telah dibangun. Berdasarkan pemecah masalah yang ditawarkan adalah pendekatan menang-menang atau win-win solution, yang di dalamnya terdapat kemampuan memahami situasi sosial dan etika sosial sehingga seseorang mampu menyesuaikan diri dengan situasi dan kondisi. Indikatornya yaitu kesadaran diri, pemahaman situasi, etika sosial dan keterampilan pemecahan masalah; (3) sosial communication (penguasaan keterampilan komunikasi sosial) merupakan kegiatan individu untuk menggunakan proses komunikasi dalam menjalin dan membangun hubungan interpersonal yang sehat. Sarana yang dipakai dalam proses menciptakan, membangun dan mempertahankan relasi sosial adalah melalui proses komunikasi verbal, nonverbal maupun komunikasi melalui penampilan fisik. Indikatornya yaitu komunikasi efektif dan mendengarkan efektif.

John Dewey ${ }^{14}$ mengungkapkan bahwa pengetahuan harus berasal dari sesuatu yang diimplementasikan dalam tindakan-tindakan yang

${ }^{13} \mathrm{D}$ Wahyudi, "Pembelajaran IPS Berbasis Kecerdasan Intrapersonal Dan Interpersonal Dan Eksistensial," Jurnal Pendidikan 1, no. 11 (2011), hlm. 37, http://jurnal.upi.edu/file/4-Deddy_Wahyudi.pdf.

${ }^{14}$ Muhmidayeli, Filsafat Pendidikan (Bandung: Refika Aditama, 2013), hlm. 45. 
berguna bagi pemecahan berbagai problematika yang timbul di masyarakat. Selain itu, Joyce ${ }^{15}$ juga berpendapat bahwa setiap siswa harusnya bisa bekerja sama dengan teman sekelasnya dalam kelompok belajar yang ditentukan oleh gurunya, agar dapat mengerti akan suasana yang terjadi di sekitarnya untuk mendapatkan sesuatu yang bermanfaat demi mengembangkan dirinya. Robert Bolton ${ }^{16}$ mengungkapkan bahwa $80 \%$ orang-orang gagal dalam pekerjaannya karena memiliki sikap acuh dengan orang-orang yang ada di sekitarnya. Tidak memahami suasana dan keadaan yang sedang terjadi di lingkungannya.

Pada dasarnya dalam proses pembelajaran, kecerdasan interpersonal dianggap perlu, sebab manusia adalah makhluk sosial dan tak mampu hidup sendiri. Komunikasi yang dibangun dengan baik akan menimbulkan sikap positif dan dapat menjadi tolak ukur dalam berkerja sama di kelas. Oleh sebab itu, dengan memiliki kecerdasan interpersonal seseorang akan menghasilkan koneksi yang bermanfaat antar pribadi dan dapat memberikan keuntungan bagi suatu kelompok dan yang terpenting bagi dirinya.

Berdasarkan uraian di atas, dapat disimpulkan bahwa siswa yang memiliki kecerdasan interpersonal tinggi akan mendapatkan relasi yang berguna antar pribadi dan mampu memahami keadaan satu sama lain. Siswa yang mempunyai kecerdasan interpersonal tinggi mampu bekerja sama dan mudah berinteraksi sehingga berpengaruh terhadap sikap sosial siswa.

Indonesia merupakan negara yang mempunyai keragaman agama, suku, budaya, dan sebagainya. Untuk itu, sebagai makhluk sosial hendaknya dapat bersosialisasi terhadap orang lain meskipun agama

15Muhmidayeli, 45.

16T Amstrong, 7 Kinds of Smart (Jakarta: Gramedia Pustaka Utama, 2002), 17. 
Tasnim Lubis ${ }^{1}$, Nashran Azizan², Maulana Arafat Lubis ${ }^{3}$

ataupun sukunya berbeda. Allah SWT memerintahkan hambanya untuk saling mengetahui satu sama lain, seperti yang dijelaskan dalam firmanNya di QS. Al-Hujurat ayat 13:

"Hai manusia, sesungguhnya kami menciptakan kamu dari seorang laki-laki dan seorang perempuan dan menjadikan kamu berbangsa-bangsa dan bersuku-suku supaya kamu saling kenal mengenal. Sesungguhnya yang paling mulia di antara kamu di sisi Allah ialah yang paling bertakwa dia antara kamu. Sesungguhnya Allah Maha Mengetahui Lagi Maha Mengenal"

Dari terjemahan ayat di atas menunjukkan bahwa Allah SWT memerintahkan hambanya untuk dapat berinteraksi dengan baik dengan manusia lainnya, meskipun terdapat banyak perbedaan. Ketika manusia dapat berinteraksi dengan baik terhadap orang di sekiatarnya, maka ia dapat memberikan manfaat satu sama lain. Untuk itu, kecerdasan interpersonal perlu dibangun dalam diri seseorang agar dapat memberikan hal positif berupa kedamaian di dunia dan di akhirat.

Salah satu dampak dari rendahnya kecerdasan interpersonal, yaitu seseorang merasa sungkan untuk berhubungan dengan selainnya sehingga merasa tidak butuh akan kehadiran orang lain dalam hidupnya. Sementara dalam Islam manusia diajarkan untuk saling berinteraksi satu sama lain untuk meraih kebaikan. Rasa tidak butuh terhadap orang lain menjadi dampak negatif dalam diri seseorang untuk meningkatkan kecerdasan interpersonal dalam dirinya. Maka sebagai makhluk sosial hendaknya dapat memahami situasi dan kondisi yang terjadi di masyarakat sehingga nantinya dapat memberikan dampak positif bagi orang lain.

Maka dari itu sekolah menjadi tempat untuk mengembangkan kecedasan interpersonal siswa, meskipun pada dasarnya setiap siswa 
memiliki karakteristik yang berbeda. Keterampilan-keterampilan dalam mengembangkan kecerdasan interpersonal harus diterapkan, guna memudahkan pendidik dalam mengintegrasikan dimensi kecerdasan interpersonal pada proses pembelajaran. Islam juga mempunyai aturan bergaul yang tepat, agar seseorang dapat berhubungan dengan baik terhadap selainnya walaupun mereka memiliki karakteristik diri yang berbeda-beda. Hal ini dapat dilihat pada surah Al-Furqon ayat 63 yang artinya:

"Dan hamba-hamba Tuhan yang Maha Penyayang itu (ialah) orangorang yang berjalan di atas bumi dengan rendah hati dan apabila orangorang jahil menyapa mereka, mereka mengucapkan kata-kata (yang mengandung) keselamatan".

Dari terjemahan ayat di atas, maka dapat disimpulkan bahwa Allah SWT memerintahkan kepada hambanya agar memiliki kepribadian yang baik. Memiliki sifat rendah hati sekalipun diganggu oleh orang-orang jahil, tidak membalas kejahatan dengan kejahatan melainkan dengan kebaikan. Siswa yang memiliki kecerdasan interpersonal tinggi mampu memahami kondisi dan situasi sekalipun hal itu tidak menyenangkan hati. Islam mengajarkan kepada orang untuk memiliki hati yang baik. Karena kebaikan akan dibalas juga dengan kebaikan. Namun, kita tidak seharusnya membalas kejahatan dengan kejahatan. Alangkah lebih baiknya ketika kita mampu membalas kejahatan orang lain dengan kebaikan yang kita miliki. Untuk itu pendidik harus lebih menggalakkan sikap siswa agar menjadi lebih baik lagi melalui implementasi kecerdasakan interpersonal dalam proses pembelajaran. 
Tasnim Lubis' ${ }^{1}$ Nashran Azizan², Maulana Arafat Lubis ${ }^{3}$

Selanjutnya, sekolah dasar (SD) merupakan jenjang pertama pada lembaga pendidikan formal di Indonesia. Rentang usia siswa SD sekitar 712 tahun. Undang-Undang Sistem Pendidikan Nasional (UU Nomor 20 Tahun 2001) Pasal 17 mendeskripsikan pendidikan dasar sebagai berikut: (1) Pendidikan dasar merupakan awal pendidikan yang melandasi pendidikan menengah atau setelahnya; (2) Pendidikan dasar berbentuk sekolah dasar (SD) dan Madrasah Ibtidaiyah (MI) serta Sekolah Menengah Pertama (SMP) dan Madrasah Tsanawiyah (MTs).

Menurut Basset dkk17, karakteristik siswa SD secara umum: (1) memiliki rasa keingintahuan yang kuat dan tertarik pada dunia sekitar yang mengelilingi diri mereka sendiri, (2) senang bermain dan bergembira riang, (3) suka mengatur diri untuk menangani berbagai hal, (4) bergetarnya perasaan dan terdorong untuk berprestasi sebagaimana mereka tidak suka mengalami ketidakpuasan dan menolak kegagalan-kegagalan, (5) belajar secara efektif ketika merasa puas dengan situasi yang terjadi, (6) belajar dengan cara bekerja, mengobservasi, berinisiatif, dan mengajar anak-anak lainnya.

Berdasarkan karakteristik tersebut dapat disimpulkan bahwa siswa SD memiliki rasa ingin tahu yang tinggi serta mau bekerja sama pada setiap proses pembelajaran. Hal ini menjadi perhatian bagi pendidik untuk dapat mengembangkan kemampuan dan kecerdasan interpersonal siswa di era Revolusi Industri 4.0.

Pada dasarnya siswa SD memiliki karakteristik yang berbeda-beda. Maka dari itu pendidik perlu memberikan penilaian terhadap kecerdasan interpersonal di setiap kegiatan proses pembelajaran. Ini dilakukan agar pendidik mengetahui bagaimana sebenarnya kecerdasan interpersonal

17Mulyani Sumantri and Johan Permana, Strategi Belajar Mengajar (Bandung: CV. Maulana, 2011), 11. 
masing-masing siswa, sebab kecerdasan interpersonal merupakan kecerdasan yang berhubungan dengan perilaku sosial, maka seorang siswa mampu berkomunikasi dengan baik dan peduli terhadap situasi dan kondisi yang terjadi di sekitarnya serta mampu mengembangkan keterampilan sosialnya kepada antar teman, guru dan lingkungan masyarakat.

Ketika siswa memiliki kecerdasan interpersonal tinggi maka siswa akan mudah beradaptasi dengan perubahan zaman yang semakin berkembang pesat. Sehebat apapun perkembangan zaman, pendidik dan siswa dapat bekerja sama dan mampu menjadikannya sebagai tantangan dan peluang tanpa mengesampingkan kecerdasan interpersonal atau sikap sosial yang sesungguhnya.

Munculnya revolusi industri 4.0 disebut era digital atau era disrupsi teknologi dengan makna penggunaan teknologi dari berbagai bidang, salah satunya Pendidikan menjadi sesuatu yang harus dilalui 18. Hal ini dinyatakan oleh Rhenald Kasali 19 bahwa era disrupsi adalah zaman di mana adanya inovasi yang akan menggantikan seluruh sistem lama dengan sistem baru.

Revolusi Industri 4.0 membawa perubahan bagi pembangunan bangsa. Konsep revolusi industri pertama kali diperkenalkan oleh Klaus Schwab. Beliau merupakan ekonom terkenal dan berasal dari Negara Jerman sekaligus penemu World Economic Forum(WEF) yang ditulis

18Maulana Arafat Lubis, "PENGEMBANGAN KARAKTER SISWA SEKOLAH DASAR BERBASIS PANCASILA DI ERA REVOLUSI INSDUSTRI 4.0," INA-Rxiv, 2019, https://doi.org/https://doi.org/10.31227/osf.io/8jya9.

19 Maulana Arafat Lubis, Syafrilianto, and Nashran Azizan, "PENGGUNAAN MEDIA PEMBELAJARAN BERBASIS ANDROID BAGI SISWA SD/MI DI ERA REVOLUSI INDUSTRI 4.0," INA-Rxiv, 2019, https://doi.org/https://doi.org/10.31227/osf.io/5xq6k. 
Tasnim Lubis ${ }^{1}$, Nashran Azizan², Maulana Arafat Lubis ${ }^{3}$

dalam bukunya, The Fourth Industrial Revolution, mengungkapkan bahwa revolusi industri 4.0 secara mendasar bisa mengubah cara kita hidup, kemudian ketika kita melakukan sebuah pekerjaan, dan berinteraksi satu sama lain.

Revolusi industri 1.0 ditandai dengan penggunaan mesin berbasis manufaktur terjadi pada akhir abad ke-18 (pada tahun 1750-1850), revolusi industri 2.0 ditandai dengan produksi massal dengan mesin bertenaga listrik terjadi pada awal abad ke-19, revolusi industri 3.0 ditandai dengan tekonologi informasi dan elektronika guna otomasi produksi terjadi diawal abad ke- 20, dan revolusi industri 4.0 ditandai dengan integrasi online dengan produksi industri untuk peningkatan efisiensi proses industri.

Saat ini Indonesia sedang menghadapi revolusi industri yang dikenal dengan revolusi industri 4.0. Salah satu era ini ditandai dengan perkembangan teknologi yang berkembang begitu pesat. Teknologi mengubah hidup manusia menjadi lebih modern. Bukan hanya modern, teknologi juga mempermudah hidup manusia dari berbagai aspek. Salah satunya, pendidikan. Pendidikan merupakan senjata dalam memajukan suatu negara. Namun, di samping itu perkembangan teknologi memberikan dampak negatif kepada penggunanya, khususnya teknologi yang digunakan oleh siswa sekolah dasar (SD). Era revolusi industri 4.0 tak jarang pengguna smartphone adalah siswa SD. Smartphone yang dulunya hanya digunakan pada orang dewasa kini sudah digunakan oleh siswa SD. Penggunaan smartphone memberikan dampak positif dan negatif bagi siswa SD. Salah satunya, aplikasi yang terdapat dalam smartphone. Penyalahgunaan smartphone membuat kecerdasan interpersonal siswa menjadi rendah.

Siswa yang sibuk dengan smartphonenya seringkali tidak memperdulikan situasi dan kondisi yang terjadi di sekitarnya. Hal ini 
menjadi perhatian besar bagi para guru sebagai pendidik. Maka dengan perkembangan teknologi yang begitu pesat pendidik harusnya mampu menggunakan teknologi di setiap proses pembelajaran sebagai bahan ajar, media dan sumber belajar bagi siswa SD. Pendidik bisa mengarahkan penggunaan smartphone ke dalam hal-hal positif. Revolusi industri 4.0 ini merupakan era disrupif, dimana era ini bisa menggeser atau menggantikan posisi yang sudah ada. Untuk itu revolusi industri 4.0 harusnya dijadikan tantangan dan peluang bagi pendidikan agar tetap stabil dalam mengembangkan kemampuan dan kecerdasan interpersonal siswa SD agar nantinya dapat menjadi sumber daya yang dapat diandalkan serta dapat bersaing dengan perubahan zaman yang terus berkembang.

Untuk itu sekolah merupakan tempat untuk mengembangkan kemampuan dan kecerdasan interpersonal siswa. Secanggih apapun perubahan teknologi yang terjadi, peran guru sebagai pendidik tetap tidak bisa tergantikan oleh kemajuan teknologi tersebut ketika mampu berapdatasi dengan baik.

\section{Penutup}

Kecerdasan interpersonal merupakan hal yang tidak dapat dipisahkan pada proses pembelajaran. Siswa tidak bisa hanya dituntut untuk menjadi pintar melainkan dapat memiliki kepribadian yang akhlakul karimah. Ini dapat dilihat dari sikap mereka dalam berinteraksi dengan teman sebaya, pendidik, lingkungan sekolah dan masyarakat.

Revolusi industri 4.0 yang dikenal dengan era digital memiliki banyak manfaat pada perkembangan teknologi. Salah satunya, Smaprtphone atau yang sering dikatakan dengan sebutan ponsel cerdas. Smartphone merupakan ponsel cerdas yang memiliki fitur canggih. Fiturfitur yang ada pada smartphone, antara lain telepon, SMS, internet, e- 
Tasnim Lubis ${ }^{1}$, Nashran Azizan², Maulana Arafat Lubis ${ }^{3}$

book viewer, aplikasi pengedit dokumen, serta game-game online dan offline. Kemajuan yang pesat ini justru menimbulkan rasa individualis. Tak jarang pengguna Smaprtphone sudah hampir digunakan oleh seluruh khalayak masyarakat mulai dari dewasa hingga ke anakanak salah satunya siswa sekolah dasar. Orang tua membebaskan anaknya untuk menggunakan Smaprtphone agar memudahkan komunikasi antar mereka. Namun, di samping itu hal ini memiliki dampak negatif, dikarenakan pengawasan yang tidak 24 jam membuat siswa merasa bebas menggunakan smartphone yang telah dimilikinya. Hal ini juga menyebabkan terjadinya krisis komunkasi antar teman. Siswa lebih sibuk dengan smaprtphone yang ada digenggamannya dibandingkan dengan teman yang ada di sebelahnya. Apalagi jika dilihat dengan aplikasi game yang membuat mereka asik sehingga tidak menghiraukan situasi dan kondisi yang ada di sekitarnya, ini akan menjadi perhatian yang penting bagi dunia pendidikan.

Penanaman kecerdasan interpersonal harus lebih digalakkan lagi agar krisis komunikasi dapat diatasi dengan baik. Selanjutnya pada perkembangan agama. Siswa tak jarang sering mengabaikan adzan ketika berkumandang. Mereka lebih mementingkan game ataupun chattingan yang terdapat pada aplikasi smartphone. Kurangnya rasa kasih sayang antar teman, sehingga ada yang tega ketika melihat temannya sedih atau sedang mengalami duka. Tidak mau membantu temannya ketika mengalami kesulitan. Padahal islam sangat mengajarkan untuk saling menyayangi dan membantu satu sama lain dala meraih kebaikan. Pada dasarnya revolusi industri 4.0 memberikan tantangan dan peluang bagi dunia pendidikan. Hal ini tentunya harus disikapi dengan bijak. Salah satunya dengan mendongkrak kecerdasan interpersonal siswa terutama dalam perspektif Islam. 
Peran Kecerdasan Interpersonal dalam Perspektif Islam....

\section{Daftar Pustaka}

Amstrong, T. 7 Kinds of Smart. Jakarta: Gramedia Pustaka Utama, 2002.

Dariyo, Agoes. Dasar Dasar Pedagogi Modern. Jakarta: Indeks, 2013.

Ervani, Yessanty Arie, and Ellya Rakhmawati. "Upaya Meningkatkan Kecerdasan Interpersonal Melalui Metode Cooperative Play Pada Kelompok B Di Daqu School International Preschool Semarang Tahun Pelajaran 2014/2015." Jurnal Penelitian PAUDIA 3, no. 2 (2014), hlm. 191-206. http://journal.upgris.ac.id/index.php/paudia/article/view/517.

Hamalik, Oemar. Kurikulum Dan Pembelajaran. Jakarta: Bumi Aksara, 2012.

Imanita, M. "Pengaruh Metode Pembelajaran Dan Kecerdasan Interpersonal Terhadap Hasil Belajar Sejarah Siswa SMA." Jurnal Pendidikan Sejarah 3, no. 1 (2014), hlm. 45-54. http://journal.unj.ac.id/unj/index.php/jps/article/view/992.

Kagermann, H, W.D Lukas, and W Wahlster. "Industrie 4.0: Mit Dem Internet Der Dinge Auf Dem Weg Zur 4. Industriellen Revolution," $2011 . \quad$ http://www.wolfgang-wahlster.de/wordpress/wpcontent/uploads/Industrie_4_0_Mit_dem_Internet_der_Dinge_auf_de m_Weg_zur_vierten_industriellen_Revolution_2.pdf. 
Tasnim Lubis', Nashran Azizan², Maulana Arafat Lubis ${ }^{3}$

Lubis, Maulana Arafat. "PENGEMBANGAN KARAKTER SISWA SEKOLAH DASAR BERBASIS PANCASILA DI ERA REVOLUSI INSDUSTRI 4.0." INA-Rxiv, 2019. https://doi.org/https://doi.org/10.31227/osf.io/8jya9.

Lubis, Maulana Arafat, Syafrilianto, and Nashran Azizan. "PENGGUNAAN MEDIA PEMBELAJARAN BERBASIS ANDROID BAGI SISWA SD/MI DI ERA REVOLUSI INDUSTRI 4.0.” INA-Rxiv, 2019. https://doi.org/https://doi.org/10.31227/osf.io/5xq6k.

Manurung, N. "Pemanfaatan Multiple Intigence Dalam Proses Pembelajaran." Jurnal Keguruan Vol. 1, No. 1 (2013), hlm. 49-56.

May, Lwin, and Dkk. How To Multiply Your Child's Intelligence. Yogyakarta: Indeks, 2008.

Muhmidayeli. Filsafat Pendidikan. Bandung: Refika Aditama, 2013.

Ngalim, Purwanto. IImu Pendidikan Teoritis Dan Praktis. Bandung: PT Remaja Rosdakarya, 2007.

Sari, Suci Perwita. "Hubungan Verbal Bullying Terhadap Kecerdasan Interpersonal Siswa Di SDN 104206 Sei Rotan T.A. 2013/2014." Universitas Negeri Medan, 2014.

Sumantri, Mulyani, and Johan Permana. Strategi Belajar Mengajar. Bandung: CV. Maulana, 2011. 
Peran Kecerdasan Interpersonal dalam Perspektif Islam....

Uno, H, and M Kuadrat. Mengelola Kecerdasan Dalam Pembelajaran. Jakarta: Bumi Aksara, 2009.

Wahyudi, D. "Pembelajaran IPS Berbasis Kecerdasan Intrapersonal Dan Interpersonal Dan Eksistensial." Jurnal Pendidikan Vol. 1, No. 11 (2011), hlm. 33-45. http://jurnal.upi.edu/file/4-Deddy_Wahyudi.pdf.

Zainuddin. "Eksperimentasi Model Pembelajaran Kooperatif Tipe Two Stay Two Stray Dan Number Head Together Pada Materi Pokok Fungsi Ditinjau Dari Kecerdasan Interpersonal Siswa Kelas VIII SMP Negeri Sekota Surakarta." Universitas Sebelas Maret, 2014. 